\title{
Sorafenib and hepatic arterial infusion chemotherapy for unresectable advanced hepatocellular carcinoma: A comparative study
}

\author{
YASUNARI HIRAMINE ${ }^{1,2}$, HIROFUMI UTO ${ }^{2}$, YASUSHI IMAMURA ${ }^{1}$, KAZUAKI TABU $^{1,2}$, \\ YOSHIROU BABA ${ }^{1}$, TAKUYA HIWAKI ${ }^{1}$, YUKIHIKO SHO ${ }^{1}$, KENJI TAHARA ${ }^{1}$, HIROFUMI HIGASHI ${ }^{3}$, \\ TUTOMU TAMAI $^{2}$, MAKOTO OKETANI ${ }^{2}$, AKIO IDO $^{2}$ and HIROHITO TSUBOUCHI ${ }^{2}$

\begin{abstract}
${ }^{1}$ Department of Internal Medicine, Kagoshima Kouseiren Hospital, Kagoshima 890-0061; ${ }^{2}$ Department of Digestive and Lifestyle-Related Disease, Kagoshima University Graduate School of Medical and Dental Sciences, Kagoshima 890-8544; ${ }^{3}$ Department of Hygiene and Public Health, School of Medicine, National Institute of Fitness and Sports in Kanoya, Kanoya, Kagoshima 891-2393, Japan
\end{abstract}

Received January 21, 2011; Accepted March 14, 2011

DOI: $10.3892 / \mathrm{etm} .2011 .237$

\begin{abstract}
Sorafenib is a kinase-targeted drug that has high efficacy for advanced hepatocellular carcinoma (HCC). The aim of the present study was to determine whether sorafenib is more effective than hepatic arterial infusion chemotherapy (HAIC) for HCC. Twenty patients treated with sorafenib (sorafenib group) initiated at $800 \mathrm{mg} /$ day and 45 patients treated with HAIC (HAIC group) for unresectable Child-Pugh A advanced HCC were investigated retrospectively. The treatment effect was assessed using the Response Evaluation Criteria in Solid Tumors (RECIST). As a result, the overall response rate was significantly lower in the sorafenib group than in the HAIC group $(\mathrm{P}=0.03)$, while the disease control and survival rates did not differ between the two groups. In the sorafenib group, treatment was discontinued in 19 patients, including 12 due to side effects. In subgroups of patients treated with sorafenib, the survival rate was significantly lower in patients $(n=11)$ administered sorafenib for $<60$ days compared to those $(n=9)$ treated for $\geq 60$ days. A shorter treatment period ( $<60$ days) was an independent risk factor for unfavorable survival [hazard ratio (HR), 3.34; 95\% confidence interval (CI), 1.45-7.66 vs. HAIC], while survival in patients treated with sorafenib for $\geq 60$ days did not differ from those treated with HAIC (HR, 0.79; 95\% CI, $0.27-2.34)$. In conclusion, the disease control and survival rates of patients treated with sorafenib for advanced HCC were comparable to such rates in patients treated with HAIC.
\end{abstract}

Correspondence to: Dr Hirofumi Uto, Department of Digestive and Lifestyle-Related Disease, Kagoshima University Graduate School of Medical and Dental Sciences, 8-35-1 Sakuragaoka, Kagoshima 890-8520, Japan

E-mail: hirouto@m2.kufm.kagoshima-u.ac.jp

Key words: hepatocellular carcinoma, sorafenib, hepatic arterial infusion chemotherapy, prognosis, side effect
However, the prognosis was poor when long-term sorafenib treatment was not possible due to side effects, demonstrating the importance of patient selection for sorafenib treatment.

\section{Introduction}

Hepatocellular carcinoma (HCC) is a highly prevalent cancer worldwide, and is frequently caused by infection with hepatitis B or C. Early-stage HCC can be cured by surgery or local ablation, and inhibition of recurrence has been achieved using antiviral agents. However, prevention of HCC recurrence after radical treatment remains insufficient. Many HCC cases are in an advanced stage or unresectable at the time of diagnosis. Moreover, although unresectable advanced HCC can be treated with hepatic arterial infusion chemotherapy (HAIC) and systemic chemotherapy, the therapeutic effects are limited (1-3) and the prognosis of advanced cases of HCC is poor.

Large-scale randomized placebo-controlled trials have shown that sorafenib, a multi-kinase inhibitor, prolongs overall and disease progression-free survival in patients with HCC $(4,5)$. Based on these findings, sorafenib is recommended for treatment of advanced stage HCC (Child-Pugh A-B, grade 1-2 performance status cases with portal tumor thrombus, lymph node metastasis or distant metastasis) in the Barcelona Clinic Liver Cancer (BCLC) staging system-based therapeutic strategy for HCC (6). In Japan, the use of sorafenib for unresectable hepatocellular carcinoma was approved in May 2009, and the indication for sorafenib may be expanded in the future. However, to date, the effect of sorafenib has only been compared with untreated groups, and further evidence is required to position sorafenib in the treatment algorithm for $\mathrm{HCC}$, for which various treatment methods are available $(7,8)$.

The response rate of advanced HCC to HAIC is approximately $30-40 \%$ (9-16), and HAIC (as well as sorafenib) is recommended for treatment of advanced HCC, particularly in Japan $(17,18)$. However, comparison of the effects of sorafenib with other treatment methods for HCC has not been 
carried out. Therefore, in the present study, we retrospectively compared the efficacy of sorafenib for unresectable advanced HCC with that of HAIC.

\section{Patients and methods}

Patients. A total of 107 Child-Pugh class A patients with advanced HCC were treated at Kagoshima Kouseiren Hospital between July 1, 2004 and May 31, 2010; 72 patients were treated with HAIC and 35 with sorafenib. Diagnosis of HCC was established based on typical radiographic evidence and tumor markers such as $\alpha$-fetoprotein (AFP) and des- $\gamma$ carboxy prothrombin [DCP, also known as protein induced by vitamin $\mathrm{K}$ absence or antagonist (PIVKA-II)].

Of the 107 patients, 65 were selected for further analysis based on the criteria below. These patients included 45 treated with HAIC and 20 treated with sorafenib. All 65 patients had advanced HCC unsuitable for surgical resection, liver transplantation, or nonsurgical interventions [such as radiofrequency ablation or transcatheter arterial chemoembolization (TACE)] because of multiple tumors involving both lobes of the liver or portal invasion in the first or main portal branch (19). Other eligibility criteria included Eastern Cooperative Oncology Group (ECOG) performance status 0 or 1 for sorafenib or 0 to 2 for HAIC, no other serious medical condition, no history of systematic chemotherapy with sorafenib, no concurrent malignancy of another type, and previously described laboratory findings for sorafenib (20). In addition, we excluded patients who had more than two distant metastases or a distant metastasis of size $>1 \mathrm{~cm}$.

The average total and daily alcohol consumption was calculated assuming that $633 \mathrm{ml}$ of beer or $120 \mathrm{ml}$ of shochu (a traditional Japanese distilled spirit) contains $25 \mathrm{~g}$ of ethanol, which is the typical ethanol content of Japanese beer and shochu. Excess alcohol intake was defined as $>75 \mathrm{~g}$ of ethanol per day, using data obtained by questionnaire. Body mass index (BMI) was calculated by dividing body weight $(\mathrm{kg})$ by the square of the height $\left(\mathrm{m}^{2}\right)$. Informed consent was obtained from all patients before treatment. This study was performed retrospectively and was approved by the Ethics Committee of the Kagoshima Prefectural Federation of Agricultural Cooperatives for Health and Welfare.

Treatment and dose modification. Sorafenib for unresectable HCC was approved in Japan in May 2009. Before this date, all patients underwent HAIC, while after May 2009 patients were treated with sorafenib or HAIC. HAIC was administered in three regimens. Regimen A consisted of daily cisplatin ( $5 \mathrm{mg} /$ $\mathrm{m}^{2}$ ) followed by 5 -fluorouracil (5-FU, $250 \mathrm{mg} /$ body) on days $1-5,8-12$ and 15-19, with days $6,7,13,14,20$ and 21 as rest days. Cisplatin and 5-FU were administered by a mechanical infusion pump through implanted reservoir over 1 and $23 \mathrm{~h}$, respectively (21). Regimen B consisted of cisplatin $(50 \mathrm{mg} /$ body), mitomycin C (MMC, $10 \mathrm{mg} /$ body) and epirubicin (EPI, $30 \mathrm{mg} /$ body) as a bolus injection on day 1, and daily cisplatin $\left(5 \mathrm{mg} / \mathrm{m}^{2}\right)$ followed by 5 -FU $(250 \mathrm{mg} /$ body $)$ on days $8-12$ and 15-19. Cisplatin and 5-FU after day 8 were administered by a mechanical infusion pump through implanted reservoir over 1 and $23 \mathrm{~h}$, respectively. Regimen $\mathrm{C}$ consisted of cisplatin (50 mg/body), MMC (10 mg/body) and EPI (30 mg/body) as

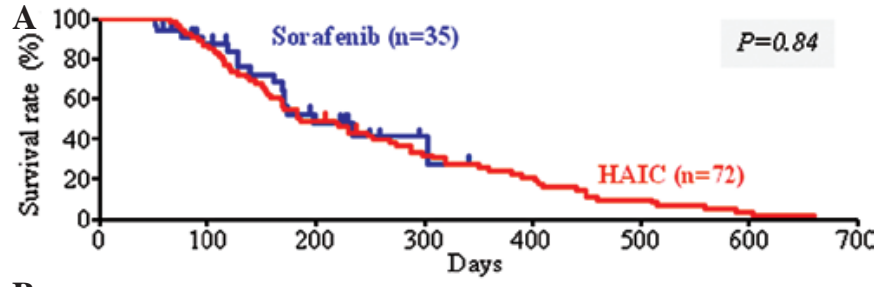

B

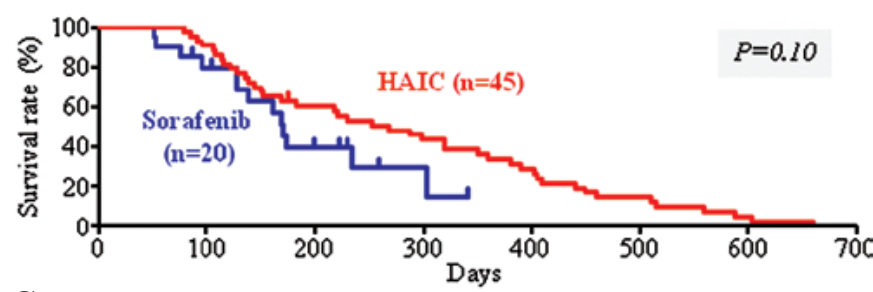

C

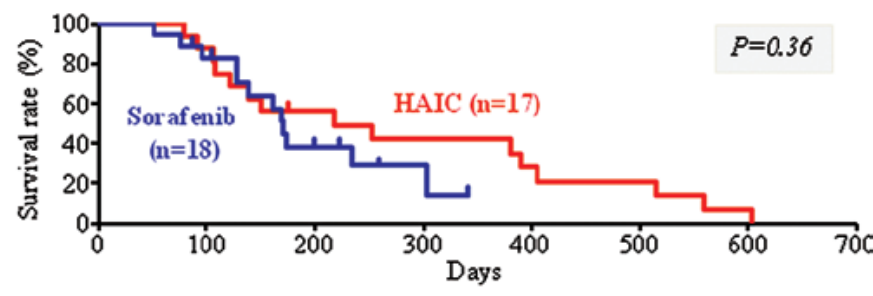

Figure 1. Accumulated survival rates of patients with advanced hepatocellular carcinoma treated with hepatic arterial infusion chemotherapy (HAIC) and sorafenib. (A) Seventy-two patients were treated with HAIC and 35 patients were treated with sorafenib at our hospital. There was no significant difference in the survival rate between the two groups ( $\mathrm{P}=0.84)$. (B) Among the patients in A, 45 treated with HAIC and 20 treated with sorafenib were selected for further analysis using the criteria described in Materials and methods. The survival rate of these two groups did not differ significantly $(\mathrm{P}=0.10)$. (C) Among the patients in $\mathrm{B}, 17$ treated with HAIC and 18 treated with sorafenib were previously treated by modalities such as transarterial chemoembolization. The survival rate of these two groups also did not differ significantly $(\mathrm{P}=0.36)$.

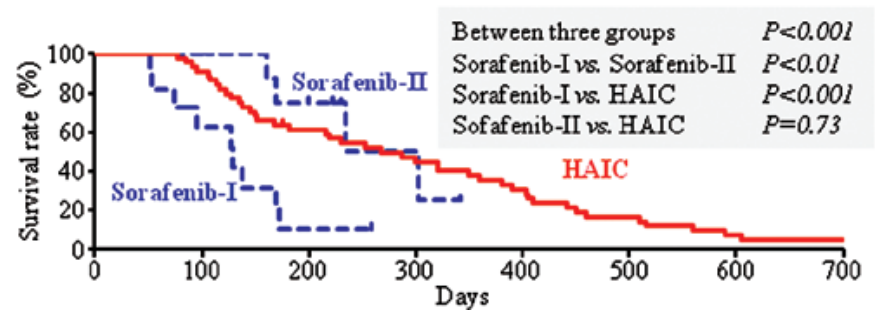

Figure 2. Accumulated survival rate of patients with advanced hepatocellular carcinoma treated with sorafenib for $<60$ days $(n=11$, sorafenib-I), sorafenib for $\geq 60$ days $(n=9$, sorafenib-II), and hepatic arterial infusion chemotherapy (HAIC). The definition of the sorafenib-I and sorafenib-II subgroups is described in Materials and methods. The survival rate was lower in the sorafenib-I subgroup compared to the sorafenib-II subgroup and HAIC group.

a bolus injection through a catheter on day 1 . All anticancer agents were administered through the common or proper hepatic artery. Regimens A, B and C were administered to 25, 12 and 8 patients, respectively, and the cycles were repeated when possible. Sorafenib was administered orally at $400 \mathrm{mg}$ twice a day. Selection of the treatment was made by each physician, patient or family members after informed consent was obtained. 
Table I. Clinical characteristics and tumor-related background factors of the advanced hepatocellular carcinoma patients treated with HAIC and sorafenib ${ }^{\mathrm{a}}$.

\begin{tabular}{|c|c|c|c|}
\hline Factor & HAIC $(n=45)$ & Sorafenib $(n=20)$ & P-value \\
\hline Age (range), in years & $69.6(47-84)$ & $69.6(44-83)$ & 0.88 \\
\hline Gender (male/female) & $0.71 / 0.29$ & $0.85 / 0.15$ & 0.35 \\
\hline Virus marker (HBV/HCV/NBNC) & $0.24 / 0.40 / 0.36$ & $0.25 / 0.50 / 0.25$ & 0.74 \\
\hline Excess alcohol intake $(+/-)$ & $0.31 / 0.69$ & $0.35 / 0.65$ & 0.77 \\
\hline Diabetes mellitus (+/-) & $0.27 / 0.73$ & $0.30 / 0.70$ & 0.77 \\
\hline Body weight (kg) & $54.6(37.8-72.5)$ & $55.9(38.4-68.9)$ & 0.87 \\
\hline Body mass index $\left(\mathrm{kg} / \mathrm{m}^{2}\right)$ & $20.6(15.8-27.1)$ & $21.9(16.0-28.4)$ & 0.69 \\
\hline Total bilirubin (mg/dl) & $1.2(0.3-2.7)$ & $1.1(0.5-1.9)$ & 0.80 \\
\hline AST (IU/l) & $74.7(22-206)$ & $80.6(25-201)$ & 0.39 \\
\hline ALT (IU/l) & $53.2(13-198)$ & $53.1(17-178)$ & 0.74 \\
\hline Serum albumin $(\mathrm{g} / \mathrm{dl})$ & $3.6(2.4-4.5)$ & $3.6(2.8-4.4)$ & 0.73 \\
\hline White blood cell $\left(\mathrm{x} 10^{3} / \mu \mathrm{l}\right)$ & $3.8(2.1-5.7)$ & $4.2(2.5-6.8)$ & 0.88 \\
\hline Neutrophils $\left(\times 10^{3} / \mu 1\right)$ & $2.3(1.1-4.1)$ & $2.6(1.3-5.0)$ & 0.82 \\
\hline Platelet count $\left(\times 10^{4} / \mu 1\right)$ & $16.3(5.3-47.7)$ & $14.0(6.1-26.2)$ & 0.48 \\
\hline Prothrombin time $(\%)$ & $81.1(56-100)$ & $87.4(58-115)$ & $<0.05$ \\
\hline$\alpha$-fetoprotein $\left(\mathrm{x} 10^{3} \mathrm{ng} / \mathrm{ml}\right)$ & $8.8(0-55.9)$ & $7.3(0-97.3)$ & 0.16 \\
\hline $\mathrm{DCP}\left(\mathrm{x} 10^{3} \mathrm{mAU} / \mathrm{ml}\right)$ & $11.5(0-176.0)$ & $11.4(0-86.8)$ & 0.92 \\
\hline Tumor diameter $(\geq 50 \mathrm{~mm} /<50 \mathrm{~mm})$ & $0.49 / 0.51$ & $0.40 / 0.60$ & 0.60 \\
\hline Tumor thrombus (Vp3 or $4 ;+/-)$ & $0.64 / 0.36$ & $0.50 / 0.50$ & 0.29 \\
\hline Distant metastasis $(+/-)$ & $0.13 / 0.87$ & $0.25 / 0.75$ & 0.29 \\
\hline Previous treatment $(+/-)$ & $0.38 / 0.62$ & $0.90 / 0.10$ & $<0.001$ \\
\hline Locoregional therapy ${ }^{\mathrm{d}}$ & $0.9(0-2)$ & $1.8(0-6)$ & 0.23 \\
\hline $\mathrm{TACE}^{\mathrm{e}}$ & $2.0(0-4)$ & $4.3(0-8)$ & $<0.001$ \\
\hline
\end{tabular}

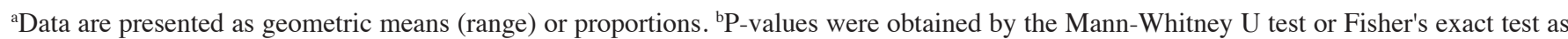
appropriate. ${ }^{\mathrm{c}}$ Defined as $>75 \mathrm{~g}$ of ethanol per day based on data obtained by questionnaire. ${ }^{\mathrm{d}}$ Average frequency (number of times) of locoregional therapy including surgery or radiofrequency ablation was evaluated. ${ }^{\mathrm{e}}$ Average frequency (number of times) of transarterial chemoembolization (TACE) was evaluated. HAIC, hepatic arterial infusion chemotherapy; HBV, positive for hepatitis B virus antigen (HBsAg); HCV, positive for anti-hepatitis $\mathrm{C}$ virus antibody (HCV Ab); NBNC, negative for both HBsAg and HCV Ab; AST, asparate aminotransferase; ALT, alanine aminotransferase; DCP, des- $\gamma$-carboxy prothrombin.

Evaluation. The therapeutic effect was assessed using the Response Evaluation Criteria in Solid Tumors (RECIST) (22). HAIC was evaluated for every course (every 4 or 6 weeks), and sorafenib treatment was evaluated every month using computed tomography (CT) and tumor markers such as AFP and DCP. Side effects were evaluated following the Common Terminology Criteria for Adverse Events (CTCAE) v3.0 (JCOG/JSCO edition) (23). The discontinuation criteria were as follows: difficulty with continuation of treatment due to disease progression or an adverse effect of grade 3 or higher, a Child-Pugh score $\geq 10$ points or uncontrollable hepatic encephalopathy, intractable ascites, total bilirubin $\geq 4.0 \mathrm{mg} / \mathrm{dl}$, or a performance status of grade 3 or 4 or worsening of the grade by $\geq 2$ categories. Additional therapies were administered on the basis of performance status, hepatic reserve capacity, tumor responses to HAIC or sorafenib, and complications.

The primary endpoint was overall survival (OS), and the secondary efficacy endpoints were overall response rate
$[\mathrm{ORR}=$ complete response $(\mathrm{CR})+$ partial response $(\mathrm{PR})]$ and disease control rate $[\mathrm{DCR}=\mathrm{CR}+\mathrm{PR}+$ stable disease $(\mathrm{SD})]$. OS was calculated from the time of the first treatment with HAIC or sorafenib until death or the last follow-up visit.

Statistical analysis. For comparison between two independent groups, the Mann-Whitney U test and Fisher's exact test were used as appropriate. For the cumulative survival and discontinuation rates, a log-rank test was performed using the Kaplan-Meier method. For multivariate analysis, logistic regression analysis and a Cox proportional hazards model were used. Cluster analysis was used to divide the sorafenib group into a limited number of maximally differing clusters based on the duration of sorafenib administration. This analysis was performed using the hierarchical agglomerative clustering method (24). A P-value $<0.05$ was considered to indicate a significant difference. The analyses were performed using XLSTAT version 2009 (Addinsoft Corp., New York, NY). 
Table II. Comparison of the therapeutic effects and discontinuation of treatment between the HAIC- and sorafenib-treated groups ${ }^{\mathrm{a}}$.

\begin{tabular}{|c|c|c|c|}
\hline Decision case $(\%)$ & $\mathrm{HAIC}(\mathrm{n}=45)$ & Sorafenib $(n=20)$ & $\mathrm{P}$-value ${ }^{\mathrm{b}}$ \\
\hline \multicolumn{4}{|l|}{ Effect: overall response } \\
\hline Complete response (CR) & $2(4.4)$ & $0 \quad(0.0)$ & \multirow[t]{4}{*}{0.150} \\
\hline Partial response (PR) & $8(17.8)$ & $0 \quad(0.0)$ & \\
\hline Stable disease (SD) & $21(46.7)$ & $13(65.0)$ & \\
\hline Progressive disease (PD) & $14(31.1)$ & $7(35.0)$ & \\
\hline ORR (CR+PR) & $10(22.2)$ & $0 \quad(0.0)$ & 0.030 \\
\hline $\mathrm{DCR}(\mathrm{CR}+\mathrm{PR}+\mathrm{SD})$ & $31(68.8)$ & $13(65.0)$ & 0.780 \\
\hline Discontinuation/continuation & $41(91.1) / 4(8.9)$ & $19(95.0) / 1(5.0)$ & 1.000 \\
\hline \multicolumn{4}{|l|}{ Reason of discontinuation } \\
\hline Disease progression & $41(91.1)$ & $7(35.0)$ & \multirow[t]{6}{*}{$<0.001$} \\
\hline Side effects & $0 \quad(0.0)$ & $12(60.0)$ & \\
\hline Liver dysfunction & 0 & 3 & \\
\hline Skin disorder & 0 & 4 & \\
\hline Diarrhea & 0 & 4 & \\
\hline Hepatic encephalopathy & 0 & 1 & \\
\hline
\end{tabular}

${ }^{a}$ Date are presented as number (proportions). ${ }^{\text {P}} \mathrm{P}$-values were obtained by Fisher's exact test as appropriate. HAIC, hepatic arterial infusion chemotherapy; ORR, overall response rate; DCR, disease control rate.

\section{Results}

Comparison of background factors, tumor factors and survival rate between the HAIC and sorafenib groups. Of the 107 patients with advanced HCC treated at our hospital between July 1, 2004 and May 31, 2010, the survival rate did not differ between the 72 patients treated with HAIC and the 35 patients treated with sorafenib (Fig. 1A). Among these patients, 45 in the HAIC group and 20 in the sorafenib group were included in further analysis. A comparison of patient background factors between the HAIC and sorafenib groups showed significant differences in prothrombin time (PT) and pre-treatment, but not in age, gender, history of excess alcohol intake, serum albumin, tumor markers, size of the main tumor, and presence or absence of portal vein tumor thrombosis in the first branch or trunk (Vp3 or Vp4, respectively) (Table I). The mean follow-up period was 317 days (55-1438 days) in the HAIC group and 166 days (51-341 days) in the sorafenib group. There was no significant difference in survival rate between the two groups (Fig. 1B), or between subgroups of patients who received pre-treatment in the HAIC and sorafenib groups (Fig. 1C).

Comparison of the therapeutic effects and treatment discontinuation between the HAIC and sorafenib groups. Assessment of the therapeutic effect using RECIST criteria (22) indicated that $\mathrm{CR}, \mathrm{PR}$ and SD were achieved in 2 (4.4\%), $8(17.8 \%)$ and $21(46.7 \%)$ cases, respectively, in the HAIC group, and in $0(0 \%), 0(0 \%)$ and $13(65.0 \%)$ cases, respectively, in the sorafenib group (Table II). Thus, the overall response rate (ORR) in the sorafenib group was significantly lower than that in the HAIC group ( 0 vs. $22.2 \%, \mathrm{P}=0.03$ ). However, there was no significant difference in the DCR between the 2 groups (65.0 vs. $68.8 \%, \mathrm{P}=0.78)$.
The treatment course, including the discontinuation rate and reasons for discontinuation, were compared between the HAIC and sorafenib groups (Table II). Treatment was discontinued in $41(91.1 \%)$ cases in the HAIC group and in $19(95 \%)$ cases in the sorafenib group, with no significant difference between the groups. However, the reason for discontinuation was disease progression including depressed hepatic reserve function due to HCC progression in all cases in the HAIC group, while the reason for discontinuation was adverse effects of grade 3 or higher in $12(60.0 \%)$ cases in the sorafenib group, showing a significantly higher occurrence of adverse effects in the sorafenib group $(\mathrm{P}<0.001)$.

Comparison of sorafenib administration for less than and greater than 60 days. Since administration was discontinued due to side effects in more than half of the patients in the sorafenib group, the cumulative discontinuation rate and duration of administration were investigated using the KaplanMeier method. Treatment was discontinued in the early phase (within 60 days) in 11/20 (55\%) of the patients. In addition, hierarchical agglomerative clustering identified two sorafenib subgroups, and on this basis the patients $(n=20)$ were divided into those for whom administration was discontinued within a period of $<60$ days ( $n=11$, sorafenib-I subgroup) and those who received sorafenib for $\geq 60$ days ( $n=9$, sorafenib-II subgroup; administration was discontinued after $>60$ days or continued). The mean durations (range) of sorafenib administration and follow-up were 31 (14-45) and 123 (51-259) days, respectively, in the sorafenib-I subgroup, and 106 (67-161) and 218 (104341) days, respectively, in the sorafenib-II subgroup. There were no significant differences in background and tumor factors between the two subgroups (Table III). However, the survival rate differed significantly among the two sorafenib subgroups and the HAIC group (multi-group log-rank test, 
Table III. Clinical characteristics of the advanced hepatocellular carcinoma patients treated with sorafenib ${ }^{\mathrm{a}}$ : Comparative evaluation of the sorafenib-I (administration <60 days) and sorafenib-II (administration $\geq 60$ days) groups .

\begin{tabular}{|c|c|c|c|}
\hline Factor & Sorafenib-I $(\mathrm{n}=11)$ & Sorafenib-II $(n=9)$ & P-value ${ }^{b}$ \\
\hline Age (range), in years & $69.9(44-83)$ & $69.2(58-78)$ & 0.57 \\
\hline Gender (male/female) & $0.82 / 0.18$ & $0.89 / 0.11$ & 1.00 \\
\hline Virus marker (HBV/HCV/NBNC) & $0.37 / 0.45 / 0.18$ & $0.11 / 0.56 / 0.33$ & 0.60 \\
\hline Excess alcohol intake $^{c}(+/-)$ & $0.27 / 0.73$ & $0.44 / 0.56$ & 0.64 \\
\hline Diabetes mellitus (+/-) & $0.18 / 0.82$ & $0.44 / 0.56$ & 0.34 \\
\hline Body weight (kg) & $53.6(38.4-68.4)$ & $58.9(48.0-68.9)$ & 0.25 \\
\hline Body mass index $\left(\mathrm{kg} / \mathrm{m}^{2}\right)$ & $21.6(16.0-28.4)$ & $22.2(18.4-24.8)$ & 0.82 \\
\hline Initial dose of sorafenib $(\mathrm{mg} / \mathrm{kg} /$ day $)$ & $15.5(6.9-17.4)$ & $13.6(5.8-15.4)$ & 0.24 \\
\hline Total bilirubin (mg/dl) & $1.2(0.5-1.8)$ & $1.0(0.6-1.9)$ & 0.21 \\
\hline AST (IU/l) & $93.5(25-201)$ & $64.9(27-116)$ & 0.32 \\
\hline ALT (IU/l) & $56.4(17-178)$ & $51.2(26-73)$ & 0.47 \\
\hline Serum albumin $(\mathrm{g} / \mathrm{dl})$ & $3.5(2.8-4.4)$ & $3.7(3.0-4.2)$ & 0.12 \\
\hline White blood cell $\left(\mathrm{x} 10^{3} / \mu 1\right)$ & $4.2(2.5-6.8)$ & $4.2(2.6-6.2)$ & 0.88 \\
\hline Neutrophils $\left(\times 10^{3} / \mu 1\right)$ & $2.6(1.4-5.0)$ & $2.5(1.3-4.6)$ & 0.88 \\
\hline Platelet count $\left(\times 10^{4} / \mu 1\right)$ & $15.4(7.0-26.2)$ & $12.4(6.1-19.1)$ & 0.15 \\
\hline Prothrombin time $(\%)$ & $85.1(72-98)$ & $90.2(58-115)$ & 0.29 \\
\hline$\alpha$-fetoprotein $\left(\mathrm{x} 10^{3} \mathrm{ng} / \mathrm{ml}\right)$ & $0.9(0-5.2)$ & $12.4(0-97.3)$ & 0.62 \\
\hline $\mathrm{DCP}\left(\mathrm{x} 10^{3} \mathrm{mAU} / \mathrm{ml}\right)$ & $17.8(0-86.8)$ & $4.2(0-27.9)$ & 0.40 \\
\hline Tumor diameter $(\geq 50 \mathrm{~mm} /<50 \mathrm{~mm})$ & $0.36 / 0.64$ & $0.44 / 0.56$ & 1.00 \\
\hline Tumor thrombus (Vp3 or $4 ;+/-)$ & $0.64 / 0.36$ & $0.33 / 0.67$ & 0.37 \\
\hline Distant metastasis $(+/-)$ & $0.27 / 0.73$ & $0.22 / 0.78$ & 1.00 \\
\hline Previous treatment $(+/-)$ & $0.91 / 0.09$ & $0.89 / 0.11$ & 1.00 \\
\hline Locoregional therapy ${ }^{\mathrm{d}}$ & $1.9(0-6)$ & $1.6(0-4)$ & 0.72 \\
\hline $\mathrm{TACE}^{\mathrm{e}}$ & $3.9(0-7)$ & $4.6(0-8)$ & 0.40 \\
\hline
\end{tabular}

${ }^{a}$ Data are presented as geometric means (range) or proportions. ${ }^{b} \mathrm{P}$-values were obtained by Mann-Whitney U test or Fisher's exact test as appro-

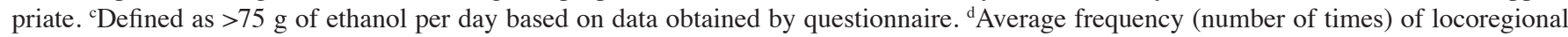
therapy including surgery or radiofrequency ablation was evaluated. ${ }^{\mathrm{e}}$ Average frequency (number of times) of transarterial chemoembolization (TACE) was evaluated. HBV, positive for hepatitis B virus antigen ( $\mathrm{HBsAg}$ ); HCV, positive for anti-hepatitis C virus antibody (HCV $\mathrm{Ab}$ ); NBNC, negative for both HBsAg and HCV Ab; AST, asparate aminotransferase; ALT, alanin aminotransferase; DCP, des- $\gamma$-carboxy prothrombin.

$\mathrm{P}<0.001$ ) (Fig. 2). A between-group comparison showed that survival was significantly shorter in the sorafenib-I subgroup compared to the sorafenib-II subgroup and the HAIC group. There was no significant difference in survival time between the sorafenib-II subgroup and the HAIC group.

The treatment discontinuation rate was $100 \%$ (11 cases) in the sorafenib-I subgroup and $89 \%$ (8 cases) in the sorafenib-II subgroup, with no significant difference between the subgroups. The reason for discontinuation was disease progression in 4 cases and side effects in 7 in the sorafenib-I subgroup, and disease progression in 3 cases and side effects in 5 in the sorafenib-II subgroup, with no significant difference between the subgroups (Table IV). However, the reasons for discontinuation of sorafenib differed from those for discontinuation of HAIC (Table II). After discontinuation of sorafenib, HAIC was performed in $2(18.2 \%)$ cases in the sorafenib-I subgroup, and in $6(66.7 \%)$ cases in the sorafenib-II subgroup $(\mathrm{P}=0.02)$. Of the 12 cases in which sorafenib was discontinued due to side effects, additional HAIC was performed in 1 of 7 cases in the sorafenib-I subgroup, but in all 5 cases in the sorafenib-II subgroup ( 14.3 vs. $100 \%, \mathrm{P}=0.02)$.

Of the factors shown in Table III, body weight, dose of sorafenib/body weight, total bilirubin, serum albumin, platelet counts and prothrombin time (\%) differed between the sorafenib-I and -II subgroups at a level of $\mathrm{P}<0.3$. These factors were subjected to multivariate logistic regression analysis, but none was found to be an independent predictor of classification into either of the two subgroups.

Prognostic factors in advanced hepatocellular carcinoma. Prognostic factors were investigated in the 65 patients with advanced HCC. Univariate analysis (log-rank test) of the 18 factors shown in Table $\mathrm{V}$ revealed that the survival rate differed significantly between the different treatment methods and between high and low DCP levels. Multivariate analysis using a Cox proportional hazards model was performed using 7 factors with $\mathrm{P}<0.3$ in the univariate analysis [age, gender, 
Table IV. Comparison of treatment discontinuation and post-treatment in the sorafenib-I and sorafenib-II groups.

\begin{tabular}{|c|c|c|c|}
\hline Decision case & $\begin{array}{l}\text { Sorafenib-I } \\
\quad(n=11)\end{array}$ & $\begin{array}{l}\text { Sorafenib-II } \\
\qquad(n=9)\end{array}$ & P-value \\
\hline Discontinuation/continuation & $11 / 0$ & $8 / 1$ & 0.45 \\
\hline \multicolumn{4}{|l|}{ Reason of discontinuation } \\
\hline Disease progression & 4 & 3 & \multirow[t]{6}{*}{1.00} \\
\hline Side effects & 7 & 5 & \\
\hline Liver dysfunction & 2 & 1 & \\
\hline Skin disorder & 2 & 2 & \\
\hline Diarrhea & 2 & 2 & \\
\hline Hepatic encephalopathy & 1 & 0 & \\
\hline \multicolumn{4}{|l|}{ Post-treatment with HAIC } \\
\hline Yes & $2(1)^{b}$ & $6(5)^{b}$ & 0.02 \\
\hline No & $9(6)^{b}$ & $2(0)^{b}$ & $(0.02)^{\mathrm{b}}$ \\
\hline
\end{tabular}

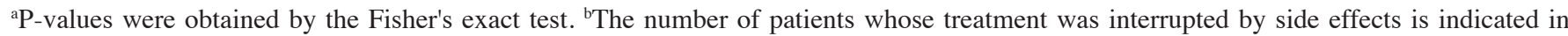
parentheses. HAIC, hepatic arterial infusion chemotherapy.

alanine aminotransferase (ALT), DCP, tumor thrombus, tumor size, and treatment method]. From this analysis, a DCP level $\geq 1000$ and discontinuation of sorafenib within 60 days (sorafenib-I subgroup) were independent risk factors contributing to a poor prognosis, and the hazard ratio in the sorafenib-I subgroup was 3.34 compared to HAIC (Table V). To eliminate the possible bias of the 4 cases in which treatment was discontinued due to marked disease progression in the sorafenib-I subgroup, survival rate and prognostic factors were analyzed for the 7 cases in which treatment was discontinued due to side effects and in which the disease condition was not markedly changed. These 7 patients were compared with the sorafenib-II subgroup and the HAIC group. In this analysis, administration of sorafenib for $<60$ days remained a poor prognostic factor by log-rank test $(\mathrm{P}=0.01 \mathrm{vs}$. sorafenib-II; $\mathrm{P}<0.01$ vs. HAIC).

\section{Discussion}

Prolongation of survival by sorafenib compared to a placebo and the efficacy of HAIC for advanced HCC have been reported $(1,2,4,5,10-12)$. However, comparison of the efficacy between sorafenib and HAIC has not been investigated. In this retrospective study, we demonstrated that the disease control rate $(\mathrm{DCR}=\mathrm{CR}+\mathrm{PR}+\mathrm{SD})$ and $\mathrm{OS}$ rate in patients with advanced unresectable HCC did not differ significantly between sorafenib treatment and HAIC, although the overall response rate $(\mathrm{ORR}=\mathrm{CR}+\mathrm{PR})$ with sorafenib treatment was lower than that for HAIC.

The prognosis was also found to be very poor when sorafenib treatment was discontinued within 60 days due to serious side effects. Although it is possible that the KaplanMeier curves for subgroups established based on events during the follow-up period (i.e., treatment cessation) included serious bias, side effects led to the discontinuation of treatment in more than half of the the cases in the sorafenib group, and many of these cases received additional treatment that may have prolonged survival. Thus, the present study suggests that early discontinuation of sorafenib was the most important factor influencing survival of patients with advanced HCC of Child-Pugh A, even if the reason for discontinuation was not disease progression.

A prospective cohort study on the combination therapy of HAIC and sorafenib for advanced HCC is currently underway (25), but the therapeutic effects of regimens including combination therapy and monotherapy of HAIC or sorafenib remain unclear. In the present study, the survival rate was comparable between HAIC and sorafenib (Fig. 1), and there was no significant difference in the DCRs (Table II). However, the overall response rate for sorafenib was $0 \%$, which was significantly lower than that for HAIC. In the SHARP study (4), the response rate of sorafenib was $2 \%$ and the DCR was $43 \%$, suggesting that the therapeutic effect depended on control of disease progression, but not on tumor size reduction. Similar findings were observed in a phase II study of sorafenib conducted in the US and Europe (26), and in a phase I study conducted in Japan (20). Our study suggests that a similar survival rate may be achieved by different treatment methods independently of the response rate when the DCR is similar. Therefore, it is important to consider not only the response rate but also the DCR, including SD cases, in the treatment of advanced HCC.

Discontinuation of HAIC occurred in 41 cases and was due to disease progression in all cases, whereas discontinuation of sorafenib occurred due to side effects in 12 cases $(60.0 \%$ of the patients treated with sorafenib) (Table II). Typical side effects of sorafenib include skin disorder (including hand-foot skin reactions), hypertension, liver dysfunction, hepatic encephalopathy, diarrhea, interstitial lung disease and hemorrhage; and the incidence of hand-foot skin reactions and diarrhea are high $(25,27)$. In our study, discontinuation of treatment was sometimes avoided by prevention and countermeasures, but discontinuation due to liver dysfunction, diarrhea and erythema multiforme was required in many cases. The 
Table V. Evaluation of the prognostic factors in the advanced hepatocellular carcinoma cases.

\begin{tabular}{|c|c|c|c|c|c|}
\hline \multirow[b]{2}{*}{ Factor (categories) } & \multicolumn{2}{|c|}{ Univariate $^{\mathrm{a}}$} & \multicolumn{3}{|c|}{ Multivariate $^{b}$} \\
\hline & $\mathrm{n}=65$ & P-value & HR & $(95 \% \mathrm{CI})$ & P-value \\
\hline Age $(\geq 70 /<70)$, in years & $35 / 30$ & 0.07 & 0.65 & $(0.35-1.19)$ & 0.16 \\
\hline Gender (male/female) & $49 / 16$ & 0.10 & 1.37 & $(0.65-2.87)$ & 0.41 \\
\hline Virus marker (HBV or HCV/NBNC) & $44 / 21$ & 0.77 & & & \\
\hline Excess alcohol intake $^{c}(+/-)$ & $21 / 44$ & 0.36 & & & \\
\hline Diabetes mellitus (+/-) & $18 / 47$ & 0.43 & & & \\
\hline $\mathrm{TB}(\mathrm{mg} / \mathrm{dl})(\geq 1.2 /<1.2)$ & $31 / 34$ & 0.35 & & & \\
\hline $\operatorname{AST}(\mathrm{IU} / \mathrm{l})(\geq 50 /<50)$ & $41 / 24$ & 0.56 & & & \\
\hline $\operatorname{ALT}(\mathrm{IU} / 1)(\geq 40 /<40)$ & $37 / 28$ & 0.23 & 1.03 & $(0.57-1.87)$ & 0.92 \\
\hline $\operatorname{ALB}(\mathrm{g} / \mathrm{dl})(\geq 3.5 /<3.5)$ & $43 / 22$ & 0.99 & & & \\
\hline $\operatorname{PLT}\left(\mathrm{x} 10^{4} \mu 1\right)(\geq 15 /<15)$ & $31 / 34$ & 0.70 & & & \\
\hline PT $(\%)(\geq 80 /<80)$ & $43 / 22$ & 0.79 & & & \\
\hline $\operatorname{AFP}(\mathrm{ng} / \mathrm{ml})(\geq 1000 /<1000)$ & $32 / 33$ & 0.98 & & & \\
\hline $\mathrm{DCP}(\mathrm{mAU} / \mathrm{ml})(\geq 1000 /<1000)$ & $36 / 29$ & 0.02 & 1.87 & $(1.03-3.38)$ & 0.04 \\
\hline Tumor thrombus (Vp3 or 4) (+/-) & $39 / 26$ & 0.19 & 1.25 & $(0.67-2.31)$ & 0.48 \\
\hline Tumor diameter $(\mathrm{mm})(\geq 50 /<50)$ & $29 / 36$ & 0.10 & 1.37 & $(0.74-2.51)$ & 0.31 \\
\hline Distant metastasis $(+/-)$ & $11 / 54$ & 0.36 & & & \\
\hline Previous treatment $(+/-)$ & $36 / 29$ & 0.37 & & & \\
\hline \multicolumn{6}{|l|}{ Treatment } \\
\hline HAIC & 45 & $<0.001$ & 1 & & \\
\hline Sorafenib- $\mathrm{I}^{\mathrm{d}}$ & 11 & & 3.34 & $(1.45-7.66)$ & $<0.01$ \\
\hline Sorafenib-II ${ }^{\mathrm{d}}$ & 9 & & 0.79 & $(0.27-2.34)$ & 0.67 \\
\hline
\end{tabular}

incidence of adverse events of grade 3 or higher caused by sorafenib was $13 \%$ in the SHARP study and $9 \%$ in the AsiaPacific study $(4,5)$, and tolerability was favorable in these studies. However, complications of liver failure and hepatic encephalopathy have been reported, and a causal relationship with development of liver failure within 3 weeks of sorafenib administration and death has been suggested.

In our study, improvement of symptoms after discontinuation was slow in patients who developed severe side effects in the early phase (administration $<60$ days), and malaise, anorexia and fever developed. Many patients died without switching to other treatments due to concomitant malnutrition and disease progression. In contrast, patients who developed no or mild side effects in the early phase were able to tolerate long-term administration ( $\geq 60$ days); even in cases in which drug administration was finally discontinued due to side effects, patients recovered from the side effects and a switch to another therapy was possible. These clinical differences may have influenced the differences in survival. Using the KaplanMeier method, the survival time was significantly shorter in the sorafenib-I subgroup compared to that in the sorafenib-II subgroup and the HAIC group (Fig. 2). In addition, short-term sorafenib administration ( $<60$ days) was an independent factor predicting a poor prognosis in multivariate analysis using a Cox proportional hazards model (Table V). The DCP level has been reported to be a factor contributing to the prognosis of HCC (28). Since the condition of the patients in the sorafenib-I subgroup influenced the prognosis, in addition to DCP, it is likely that severe early side effects of sorafenib and the associated discontinuation of treatment markedly influence the survival of patients with advanced HCC.

Only a few treatment methods are available for advanced HCC accompanied by portal invasion in the first portal branch or main portal branch $(29,30)$. In the treatment algorithm for HCC in Japan, sorafenib and HAIC are recommended for such cases of advanced HCC, but the first choice has not been specified. Based on our results, the survival rate did not differ significantly between sorafenib treatment and HAIC (Fig. 1), but the survival rate of patients was lower in patients who discontinued sorafenib treatment in the early phase of therapy 
compared to the survival rate of patients who tolerated longterm sorafenib treatment (sorafenib-II) and those treated with HAIC (Fig. 2). In addition, HAIC was applicable after side effect-associated discontinuation in some cases in patients treated with long-term sorafenib, whereas sorafenib was not administered to any patients in the HAIC group because the discontinuation of HAIC was due to disease progression in all cases. Sorafenib in combination with other treatments, including HAIC, is likely to markedly prolong the overall survival of HCC patients, including those in an advanced stage (31). However, Abou-Alfa et al concluded that the combination of sorafenib and intravenous doxorubicin is not yet indicated for routine clinical use, based on the results of a double-blind phase II multinational study (32). Based on these findings, we speculate that patients with advanced HCC accompanied by portal invasion in the first portal branch or main portal branch should first be treated with sorafenib if they are likely to tolerate sorafenib for more than 60 days. HAIC should then be considered as an additional treatment for cases in which sorafenib cannot be continued.

The effect of sorafenib has been suggested to depend on the treatment period, which is influenced by the development of serious side effects. Vincenzi et al reported that the tumor control rate was higher in patients with skin toxicity of grade 1 or higher than in those without this toxicity ( 48.3 vs. $19.4 \%$ ) (33). After dose reduction for skin toxicity, it has been suggested that the dose can be increased again in some cases after amelioration of the adverse effect (34). Thus, if long-term sorafenib administration can be achieved by controlling skin toxicity, the therapeutic effect may be further increased. Several background factors such as single nucleotide polymorphisms (SNPs) that contribute to the therapeutic effect of interferon on chronic hepatitis $\mathrm{C}$ have been reported $(35,36)$. This suggests that tolerability of long-term sorafenib administration may also be predictable before treatment, which may allow the selection of patients for whom sorafenib is appropriate. In this study, we were unable to identify any factors that significantly discriminated between patients with and without tolerability of long-term sorafenib. Thus, further analysis, including examination of SNPs, is required for safe and effective sorafenib treatment for HCC in an increased number of cases (37).

There were several limitations to this study. First, this was a retrospective study, and the number of cases was small; therefore, a bias due to the unbalanced number of cases cannot be ruled out. However, no previous study has compared the effect of sorafenib on advanced HCC with those of other treatments, and makes the findings valuable in the absence of other information. Second, HAIC was performed after discontinuation of sorafenib treatment due to side effects in 8 cases; therefore, the effect of sorafenib alone could not be assessed in these cases. However, less than one cycle of HAIC was performed after discontinuation of sorafenib, suggesting that the additional effect of HAIC may have been limited.

In conclusion, treatment of advanced HCC with sorafenib may achieve a survival rate equivalent to that achieved by HAIC, through control of disease progression independent of tumor size reduction. However, early discontinuation of sorafenib due to adverse effects may be associated with a poor prognosis, and further investigation of the eligibility criteria for sorafenib administration is required.

\section{References}

1. Cabibbo G, Latteri F, Antonucci M and Craxì A: Multimodal approaches to the treatment of hepatocellular carcinoma. Nat Clin Pract Gastroenterol Hepatol 6: 159-169, 2009.

2. Kim BK, Park JY, Choi HJ, Kim DY, Ahn SH, Kim JK, Lee DY, Lee KH and Han KH: Long-term clinical outcomes of hepatic arterial infusion chemotherapy with cisplatin with or without 5-fluorouracil in locally advanced hepatocellular carcinoma. J Cancer Res Clin Oncol: June 16, 2010 (Epub ahead of print).

3. Ikeda M, Maeda S, Ashihara H, Nagahama H, Tanaka M and Sasaki Y: Transcatheter arterial infusion chemotherapy with cisplatin-lipiodol suspension in patients with hepatocellular carcinoma. J Gastroenterol 45: 60-67, 2010.

4. Llovet JM, Ricci S, Mazzaferro V, Hilgard P, Gane E, Blanc JF, de Oliveira AC, Santoro A, Raoul JL, Forner A, Schwartz M, Porta C, Zeuzem S, Bolondi L, Greten TF, Galle PR, Seitz JF, Borbath I, Häussinger D, Giannaris T, Shan M, Moscovici M, Voliotis D and Bruix J: SHARP investigators study group: sorafenib in advanced hepatocellular carcinoma. N Engl J Med 359: 378-390, 2008.

5. Cheng AL, Kang YK, Chen Z, Tsao CJ, Qin S, Kim JS, Luo R, Feng J, Ye S, Yang TS, Xu J, Sun Y, Liang H, Liu J, Wang J, Tak WY, Pan H, Burock K, Zou J, Voliotis D and Guan Z: Efficacy and safety of sorafenib in patients in Asia-Pacific region with advanced hepatocellular carcinoma: a phase III randomized, double-blind, placebo-controlled trial. Lancet Oncol 10: 25-34, 2009.

6. Llovet JM, Di Bisceglie AM, Bruix J, Kramer BS, Lencioni R, Zhu AX, Sherman M, Schwartz M, Lotze M, Talwalkar J and Gores GJ: Panel of experts in HCC-design clinical trials: design and endpoints of clinical trials in hepatocellular carcinoma. J Natl Cancer Inst 100: 698-711, 2008.

7. Kudo M: The 2008 Okuda lecture: management of hepatocellular carcinoma: from surveillance to molecular-targeted therapy. J Gastroenterol Hepatol 25: 439-452, 2010.

8. Cabrera R and Nelson DR: The management of hepatocellular carcinoma. Aliment Pharmacol Ther 31: 461-476, 2010.

9. Urabe T, Kaneko S, Matsushita E, Unoura M and Kobayashi K: Clinical pilot study of intrahepatic arterial chemotherapy with methotrexate, 5-fluorouracil, cisplatin and subcutaneous interferon-alpha- $2 \mathrm{~b}$ for patients with locally advanced hepatocellular carcinoma. Oncology 55: 39-47, 1998.

10. Kuroda M, Kobayashi Y, Urawa N, Yamamoto M, Mifuji R, Araki J, Tanaka H, Horiike S, Itani T, Furjita N, Konishi M, Iwasa M, Kaito M and Adachi Y: Hepatic arterial infusion of 5-fluorouracil in combination with subcutaneous interferon-alpha for advanced hepatocellular carcinoma. Hepatogastroenterology 54: 518-521, 2007.

11. Uka K, Aikata H, Takaki S, Miki D, Kawaoka T, Jeong SC, Takahashi S, Toyota N, Ito K and Chayama K: Pretreatment predictor of response, time to progression, and survival to intraarterial 5-fluorouracil/interferon combination therapy in patients with advanced hepatocellular carcinoma. J Gastroenterol 42: 845-853, 2007.

12. Ando E, Tanaka M, Yamashita F, Kuromatsu R, Yutani S, Fukumori K, Sumie S, Yano Y, Okuda K and Sata M: Hepatic arterial infusion chemotherapy for advanced hepatocellular carcinoma with portal vein tumor thrombosis: analysis of 48 cases. Cancer 95: 588-595, 2002.

13. Tanioka H, Tsuji A, Morita S, Horimi T, Takamatsu M, Shirasaka T, Mizushima T, Ochi K, Kiura K and Tanimoto M: Combination chemotherapy with continuous 5-fluorouracil and low-dose cisplatin infusion for advanced hepatocellular carcinoma. Anticancer Res 23: 1891-1897, 2003.

14. Yoshikawa M, Ono N, Yodono H, Ichida T and Nakamura H: Phase II study of hepatic arterial infusion of a fine-powder formulation of cisplatin for advanced hepatocellular carcinoma. Hepatol Res 38: 474-483, 2008.

15. Kondo M, Nagano H, Sakon M, Yamamoto H, Morimoto O, Arai I, Miyamoto A, Eguchi H, Dono K, Nakamori S, Umeshita K, Wakasa $\mathrm{K}$, Ohmoto Y and Monden M: Expression of interferon alpha/beta receptor in human hepatocellular carcinoma. Int J Oncol 17: 83-88, 2000 . 
16. Ota H, Nagano H, Sakon M, Eguchi H, Kondo M, Yamamoto T, Nakamura M, Damdinsuren B, Wada $H$, Marubashi S, Miyamoto A, Dono K, Umeshita K, Nakamori S, Wakasa K and Monden M: Treatment of hepatocellular carcinoma with major portal vein thrombosis by combined therapy with subcutaneous interferon-alpha and intra-arterial 5-fluorouracil; role of type 1 interferon receptor expression. Br J Cancer 93: 557-564, 2005.

17. Kudo M: Current status of molecularly targeted therapy for hepatocellular carcinoma: clinical practice. Int J Clin Oncol 15: 242-255, 2010

18. Shen YC, Hsu C and Cheng AL: Molecular targeted therapy for advanced hepatocellular carcinoma: current status and future perspectives. J Gastroenterol 45: 794-807, 2010.

19. Park JY, Ahn SH, Yoon YJ, Kim JK, Lee HW, Lee do Y, Chon CY, Moon YM and Han KH: Repetitive short-course hepatic arterial infusion chemotherapy with high-dose 5-fluorouracil and cisplatin in patients with advanced hepatocellular carcinoma. Cancer 110: 129-137, 2007.

20. Furuse J, Ishii H, Nakachi K, Suzuki E, Shimizu S and Nakajima K: Phase I study of sorafenib in Japanese patients with hepatocellular carcinoma. Cancer Sci 99: 159-165, 2008.

21. Ando E, Yamashita F, Tanaka M and Tanikawa K: A novel chemotherapy for advanced hepatocellular carcinoma with tumor thrombosis of the main trunk of the portal vein. Cancer 79: 1890-1896, 1997.

22. Therasse P, Arbuck SG, Eisenhauer EA, Wanders J, Kaplan RS, Rubinstein L, Verweij J, van Glabbeke M, van Oosterom AT, Christian MC and Gwyther SG: New guidelines to evaluate the response to treatment in solid tumors. European Organization for Research and Rreatment of Cancer, National Cancer Institute of the United States, National Cancer Institute of Canada. J Natl Cancer Inst 92: 205-216, 2000.

23. Japanese translation of common terminology criteria for adverse events (CTCAE), and instructions and guidelines. Int J Clin Oncol 9 (Suppl. 3): S1-S82, 2004 (In Japanese).

24. Rouillier P, Senesse P, Cottet V, Valléau A, Faivre J and BoutronRuault MC: Dietary patterns and the adenomacarcinoma sequence of colorectal cancer. Eur J Nutr 44: 311-318, 2005.

25. Furuse J: Sorafenib for the treatment of unresectable hepatocellular-carcinoma. Biologics 2: 779-788, 2008.

26. Abou-Alfa GK, Schwartz L, Ricci S, Amadori D, Santoro A, Figer A, de Greve J, Douillard JY, Lathia C, Schwartz B, Taylor I, Moscovici M and Saltz LB: Phase II study of sorafenib in patients with advanced hepatocellular carcinoma. J Clin Oncol 24: 4293-4300, 2006.

27. Yang CH, Lin WC, Chuang CK, Chang YC, Pang ST, Lin YC, Kuo TT, Hsieh JJ and Chang JW: Hand-foot skin reaction in patients treated with sorafenib: a clinicopathological study of cutaneous manifestations due to multitargeted kinase inhibitor therapy. Br J Dermatol 158: 592-596, 2008.
28. Hakamada K, Kimura N, Miura T, Morohashi H, Ishido K, Nara M, Toyoki Y, Narumi S and Sasaki M: Des-gamma-carboxy prothrombin as an important prognostic indicator in patients with small hepatocellular carcinoma. World J Gastroenterol 14: 1370-1377, 2008

29. Bruix J and Llovet JM: Prognostic prediction and treatment strategy in hepatocellular carcinoma. Hepatology 35: 519-524, 2002.

30. Woo HY, Bae SH, Park JY, Han KH, Chun HJ, Choi BG, Im HU, Choi JY, Yoon SK, Cheong JY, Cho SW, Jang BK, Hwang JS, Kim SG, Kim YS, Seo YS, Yim HJ and Um SH: A randomized comparative study of high-dose and low-dose hepatic arterial infusion chemotherapy for intractable, advanced hepatocellular carcinoma. Cancer Chemother Pharmacol 65: 373-382, 2010.

31. Kudo M and Ueshima K: Positioning of a molecular-targeted agent, sorafenib, in the treatment algorithm for hepatocellular carcinoma and implication of many complete remission cases in Japan. Oncology 78 (Suppl. 1): S154-S166, 2010

32. Abou-Alfa GK, Johnson P, Knox JJ, Capanu M, Davidenko I, Lacava J, Leung T, Gansukh B and Saltz LB: Doxorubicin plus sorafenib vs. doxorubicin alone in patients with advanced hepatocellular carcinoma: a randomized trial. JAMA 304: 2154-2160, 2010.

33. Vincenzi B, Santini D, Russo A, Addeo R, Giuliani F, Montella L, Rizzo S, Venditti O, Frezza AM, Caraglia M, Colucci G, del Prete S and Tonini G: Early skin toxicity as a predictive factor for tumor control in hepatocellular carcinoma patients treated with sorafenib. Oncologis 15: 85-92, 2010.

34. La Vine DB, Coleman TA, Davis CH, Carbonell CE and Davis WB: Frequent dose interruptions are required for patients receiving oral kinase inhibitor therapy for advanced renal cell carcinoma. Am J Clin Oncol 33: 217-220, 2010.

35. Tanaka Y, Nishida N, Sugiyama M, Tokunaga $K$ and Mizokami M: Lambda-interferons and the single nucleotide polymorphisms: a milestone to tailor-made therapy for chronic hepatitis C. Hepatol Res 40: 449-460, 2010.

36. Okanoue $\mathrm{T}$, Itoh $\mathrm{Y}$, Hashimoto $\mathrm{H}$, Yasui $\mathrm{K}$, Minami $\mathrm{M}$, Takehara T, Tanaka E, Onji M, Toyota J, Chayama K, Yoshioka K, Izumi N, Akuta $\mathrm{N}$ and Kumada $\mathrm{H}$ : Predictive values of amino acid sequences of the core and NS5A regions in antiviral therapy for hepatitis C: a Japanese multi-center study. J Gastroenterol 44: 952-963, 2009.

37. Villanueva A, Minguez B, Forner A, Reig M and Llovet JM: Hepatocellular carcinoma: novel molecular approaches for diagnosis, prognosis, and therapy. Annu Rev Med 61: 317-328, 2010 . 